\title{
DEVELOPMENT AND VALIDATION OF A SIMPLE UV SPECTROPHOTOMETRIC METHOD FOR
} THE ESTIMATION OF SALBUTAMOL SULPHATE FROM PHARMACEUTICAL FORMULATIONS

\author{
G. R. GADEKAR ${ }^{1 *}$, S. S PATIL, R. R. SHAH, D. S. GHODKE
}

Department of Pharmaceutics, Appasaheb Birnale College of Pharmacy, South-Shivaji Nagar, Sangli-Miraj Road, Sangli 416416, India Email: gadekarganesh@gmail.com

Received: 18 May 2019, Revised and Accepted: 15 Jul 2019

\section{ABSTRACT}

Objective: The present study was undertaken to develop a rapid, simple, specific and economic ultraviolet (UV) spectrophotometric method for estimating the Salbutamol Sulphate (SS) in pharmaceutical formulations.

Methods: The analysis was performed at $\lambda$ max $276 \mathrm{~nm}$ using Sorenson's isotonic phosphate buffer pH 7 (SIPB pH 7 ) as blank/diluent. The method was validated by following the analytical performance parameters as suggested by International Conference on Harmonization (ICH) which included accuracy, precision, linearity.

Results: The drug follows the beer's lambert's law in the concentration range of $12.5-37.5 \mu \mathrm{g} / \mathrm{ml}$ and exhibited good correlation coefficient (0.9997) and excellent mean recovery. Percentage RSD for precision and accuracy of the method was found to be less than $2 \%$. This method was successfully applied for the determination of the Salbutamol Sulphate in commercial brands of Indian market and the results were in good agreement with the label claims. The developed method was suitable and specific to the analysis of Salbutamol Sulphate even in the presence of common excipients.

Conclusion: The obtained results proved that the validated method can be employed for the routine analysis of Salbutamol Sulphate in bulk as well as in the commercial formulations.

Keywords: Salbutamol sulphate, UV Spectrophotometric method, Validation, Sorenson's isotonic phosphate buffer pH 7

(C) 2019 The Authors. Published by Innovare Academic Sciences Pvt Ltd. This is an open-access article under the CC BY license (http://creativecommons.org/licenses/by/4.0/) DOI: http://dx.doi.org/10.22159/ijcpr.2019v11i5.35707

\section{INTRODUCTION}

\section{Salbutamol,}

$R S$-[4-[2-(tert-butylamino)-1-hydroxyethyl]-2(hydroxylmethyl) phenol] is a short-acting $\beta 2$-adrenergic receptor agonist used for the relief of Broncho-spasm in conditions such as asthma and chronic obstructive pulmonary disease. Salbutamol is still commonly delivered as a racemic mixture $(+,-)$. Salbutamol, even though S-Salbutamol is known to have a detrimental effect on asthma sufferers (in fact the exact opposite effect of the R Isomer). The mechanism of action involves the relaxation of bronchial smooth muscle by stimulating the $\beta 2$ adrenergic receptors. It is official in pharmacopoeia. Therefore a rapid, economic and selective method is needed, for the routine quality control analysis of pharmaceutical formulations containing salbutamol sulphate. The analysis was performed on $\lambda \max 276 \mathrm{~nm}$ using Sorenson's isotonic phosphate buffer pH 7 (SIPB pH 7) as blank/diluent. Salbutamol is available in tablets, capsules and aerosol inhalers [1].

This paper describes UV spectrophotometric method for the estimation of salbutamol sulfate from pharmaceutical formulations.

\section{MATERIALS AND METHODS}

UV-Visible spectrophotometer used in the experiment was from JASC0-550, Japan UV-Visible Double Beam Spectrophotometer. All other chemicals were used are of Laboratory grade.

\section{Materials}

Table 1 shows the list of materials obtained as a gift sample as well as purchased from commercial sources for the experimental work of this study.

Table 1: List of materials and chemicals

\begin{tabular}{ll}
\hline Name of the material/Chemical & Obtained/Purchased \\
\hline Salbutamol sulphate (SS) & Medioral Labs Ltd, Additional MIDC, Satara, Maharashtra, India. \\
Water soluble chitosan (WSC) & Marine chemicals, Cochin, Kerala, India. \\
Pluronic F-127 & Sigma-Aldrich Chemicals. \\
Monobasic Sodium phosphate (NaH2P04). H20 & Merck Specialties, Mumbai. \\
Dibasic Sodium Phosphate (Na2HPO4) & Loba Chemicals, Bombay. \\
Sodium Chloride (Extra pure) & Otto Kemi, Mumbai. \\
Acetone (HPLC and Spectroscopy grade) & Research Lab Fine chem., Mumbai. \\
$\mathrm{N}, \mathrm{N}-$ Dimethyl formamide & Thomas Baker chem. Ltd., Mumbai. \\
$\mathrm{KBr}$ & Loba Chemicals, Bombay. \\
\hline
\end{tabular}

\section{Method development}

- Selection of dissolution media

Various dissolution Medias were tested for the development of a suitable dissolution method for the dissolution study of Salbutamol Sulphate dry powder inhaler for pulmonary delivery. At last the following Medium was selected [2].
Medium: Sorenson's isotonic phosphate buffer pH 7 (SIPB pH 7)

\section{- Preparation of dissolution media (SIPB pH 7)}

Mix $40 \mathrm{ml}$ of $0.0667 \mathrm{M}$ Monobasic Sodium phosphate dihydrate (NaH2P04.2H2O) and $60 \mathrm{ml}$ of $0.0667 \mathrm{M}$ Dibasic Sodium phosphate anhydrous (Na2HPO4) the resulting $\mathrm{pH}$ will be 7 . Sodium chloride $(0.46 \mathrm{~g} / 100 \mathrm{ml})$ will be required for isotonicity. 


\section{- Preparation of standard calibration curve}

Accurately weighed and transferred about $25 \mathrm{mg}$ of Salbutamol Sulphate working standard into a $100 \mathrm{ml}$ volumetric flask. Added about $50 \mathrm{ml}$ of SIPB pH 7 and dissolved by shaking and made up the volume with SIPB $\mathrm{pH} 7$ to prepare a stock solution of concentration $250 \mu \mathrm{g} / \mathrm{ml}$. From the above stock solution of concentration of $250 \mu \mathrm{g} / \mathrm{ml}$ serial dilutions were done as mentioned in the table 2 and the absorbance of various dilutions was measured against SIPB pH 7 as a blank at $276 \mathrm{~nm}$ using the JASCO550, UV-Visible Spectrophotometer. The graph of absorbance versus concentration was plotted to get the calibration curve. Obtained data were subjected for linear regression analysis in Microsoft excel.

Table 2: Serial dilutions of salbutamol sulphate

\begin{tabular}{|c|c|c|c|}
\hline S. No. & ml withdrawn from stock solution & Diluted up to (ml) & Concentration $\mu \mathrm{g} / \mathrm{ml}$ \\
\hline 1 & 0.5 & 10 & 12.5 \\
\hline 2 & 1 & 10 & 25 \\
\hline 3 & 1.5 & 10 & 37.5 \\
\hline 4 & 2 & 10 & 5 \\
\hline 5 & 2.5 & 10 & 67.5 \\
\hline 6 & 3 & 10 & 75 \\
\hline 7 & 3.5 & 10 & 87.5 \\
\hline 8 & 4 & 10 & 100 \\
\hline 9 & 4.5 & 10 & 112.5 \\
\hline 10 & 5 & 10 & 125 \\
\hline
\end{tabular}

\section{- Preparation of test solution of marketed tablet formulation}

Twenty tablets of marketed tablet formulation of Salbutamol Sulphate were weighed; their average weights determined and were finely powdered. The correct amount of powder equivalent to $5 \mathrm{mg}$ SS was accurately weighed and dissolved in $50 \mathrm{ml}$ SIPB 7 to prepare a stock solution of concentration $100 \mu \mathrm{g} / \mathrm{ml}$. The excipients were separated by filtration. After filtration, appropriate aliquots were subjected for assay and the amount of Salbutamol sulphate was determined.

\section{Method validation [3-6] \\ Specificity}

Scanning and absorbance measurement carried out for the blank (diluents used in the method) and test solution

\section{- Precision}

Precision was determined at three levels i.e. repeatability, Intermediate precision, reproducibility. Repeatability is given as inter and intra-day precision concentrations of Salbutamol Sulphate.

Table 3: Recommended levels of precision

\begin{tabular}{ll}
\hline Component measured in a sample & Precision \\
\hline$\geq 10.0 \%$ & $\leq 2 \%$ \\
1.0 up to $10.0 \%$ & $\leq 5 \%$ \\
0.1 up to $1.0 \%$ & $\leq 10 \%$ \\
$<0.1 \%$ & $\leq 20 \%$ \\
\hline
\end{tabular}

\section{- Linearity}

The concentrations of Salbutamol Sulphate from 12.5-125 $\mu \mathrm{g} / \mathrm{ml}$ were prepared from the stock solution $(250 \mu \mathrm{g} / \mathrm{ml})$ and absorbance of measured at $276 \mathrm{~nm}$. The graph was plotted between concentration and absorbance for linearity.

\section{- Limit of detection (LOD)}

The detection limit of an analytical procedure is the lowest amount of an analyte in a sample that can be detected, but not necessarily quantitated as an exact value. The LOD may be determined by the analysis of samples with known concentrations of analyte and by establishing the minimum level (lowest calibration standard) at which the analyte can be reliably detected.

\section{Based on the standard deviation of the response and the slope}

The detection limit (DL) may be expressed as:

$$
\mathrm{DL}=\frac{3.3 \sigma}{\mathrm{S}}
$$

Where, $\sigma=$ the standard deviation of the response

$\mathrm{S}=$ the slope of the calibration curve the slope $\mathrm{S}$ may be estimated from the calibration curve of the analyte. The estimate of $\sigma$ may be carried out.

\section{Based on the calibration curve}

A specific calibration curve should be studied using samples, containing an analyte in the range of DL. The residual standard deviation of a regression line or the standard deviation of $y$ intercepts of regression lines was used as the standard deviation.

\section{- Limit of quantitation (LOQ)}

The limit of quantitation is the lowest amount of the analyte in the sample that can be quantitatively determined with defined precision under the stated experimental conditions.

Based on the standard deviation of the response and the slope

The quantitation limit (QL) may be expressed as:

$$
\mathrm{QL}=\frac{10 \sigma}{\mathrm{S}}
$$

Where, $\sigma=$ the standard deviation of the response

$\mathrm{S}=$ the slope of the calibration curve

The slope $\mathrm{S}$ may be estimated from the calibration curve of the analyte. The estimate of $\sigma$ may be carried out.

\section{Based on the calibration curve}

A specific calibration curve should be studied using samples, containing an analyte in the range of QL. The residual standard deviation of a regression line or the standard deviation of $y$ intercepts of regression lines was used as the standard deviation.

\section{- Accuracy}

Standard addition method: in the standard addition method, the sample of Salbutamol sulphate was assayed, a known amount of 
pure active Salbutamol sulphate constituent was added in test solution and the sample was again assayed in triplicate. And recovery of the drug was determined in formulation.

\section{- Recovery}

To check the accuracy of the developed method and to study the interference of formulation additives, analytical recovery experiments were carried out by standard addition method, at 50

100 and $150 \%$ level. From the total amount of drug found, the percentage recovery was calculated. Acceptance criteria: the expected recovery depends on the sample matrix, the sample processing procedure and on the analyte concentration. The mean $\%$ recovery should be within the following ranges:

\section{- Standards}

Salbutamol sulfate contains not less than $98.0 \%$ and not more than $101.0 \%$ of, (C13H21N03)2. H2SO4 calculated with reference to the dried substance.

\section{RESULTS AND DISCUSSION}

The proposed UV spectroscopic method has been developed for the determination of salbutamol sulphate from pharmaceutical formulations

The maximum absorbance $\lambda$ of salbutamol sulphate in Sorenson's isotonic phosphate buffer $\mathrm{pH} 7$ was found to be $276 \mathrm{~nm}$. The drug follows the beer's lambert's law in the concentration range of 12.5$37.5 \mu \mathrm{g} / \mathrm{ml}$. The proposed method of determination of salbutamol sulphate showed molar absorptivity is $3499.2054 \mathrm{~L}$. mol-1. $\mathrm{cm}^{-1}$. Linear regression of absorbance on concentration with the equation $\mathrm{Y}=0.00608 \mathrm{X}-0.00478$ with correlation coefficient of 0.9997 . The applicability to proposed method for the assay of Salbutamol sulphate in pharmaceutical formulation was examined by analyzing commercial formulations and the results were tabulated in table.

Accuracy was performed by recovery studies. The \% recovery value indicates that there is no interference from the excipients present in the formulation. The recovery studies are presented in the table.

Table 4: Assay result of the marketed formulation of salbutamol sulphate

\begin{tabular}{llll}
\hline Marketed formulation & Label claim (mg) & Amount obtained (mg) & Percent purity \\
\hline Asthalin-2 Tablet & 2.4 & 2.38 & 99.16 \\
\hline
\end{tabular}

Table 5: Recovery of salbutamol sulphate using proposed UV method

\begin{tabular}{llll}
\hline S. No. & Amount of drug added (mg) & Amount present & Mean ( \pm ) Amount \% of the recovery \\
\hline 1 & 0.125 & 0.373 & 99.46 \\
2 & 0.250 & 0.496 & 99.20 \\
3 & 0.375 & 0.624 & 99.84 \\
\hline
\end{tabular}

Table 6: Optical characteristic of salbutamol sulphate

\begin{tabular}{ll}
\hline Absorption maxima (nm) & $\mathbf{2 7 6}$ \\
\hline Beer's law limit (mcg/ml) & $12.5-37.5$ \\
Correlation coefficient & 0.99979 \\
Molar absorptivity (lit/mole/cm) & 3499.205462 \\
Sandell's sensitivity (mcg/Sq. cm/0.001) & 0.164809 \\
Regression equation & \\
Slope (m) & 0.006068 \\
Intercept & -0.00478 \\
\% COV & 1.219404 \\
Confidence limit with 0.05 level & 0.00478 \\
LOD & 1.349219 \\
LOQ & 4.088543 \\
\hline
\end{tabular}

Table 7: Precision interday

\begin{tabular}{|c|c|c|c|c|c|c|c|}
\hline \multirow[t]{2}{*}{ S. No. } & \multirow[t]{2}{*}{ Concentration $(\mu \mathrm{g})$} & \multicolumn{3}{|c|}{ Absorbance } & \multirow[t]{2}{*}{ Mean } & \multirow[t]{2}{*}{ Standard deviation } & \multirow[t]{2}{*}{ \% RSD } \\
\hline & & I & II & III & & & \\
\hline 1. & 12.5 & 0.0797 & 0.0784 & 0.0777 & 0.0786 & 0.001015 & 1.291208 \\
\hline 2. & 25 & 0.1485 & 0.1444 & 0.1478 & 0.1469 & 0.002193 & 1.492969 \\
\hline 3. & 37.5 & 0.2285 & 0.2220 & 0.2263 & 0.2255 & 0.003279 & 1.453977 \\
\hline 4. & 50 & 0.3032 & 0.2929 & 0.3015 & 0.2992 & 0.005522 & 1.845513 \\
\hline 5. & 67.5 & 0.3800 & 0.3754 & 0.3822 & 0.3792 & 0.00347 & 0.91505 \\
\hline 6. & 75 & 0.4610 & 0.4576 & 0.4666 & 0.46173333 & 0.004545 & 0.984246 \\
\hline
\end{tabular}

Table 8: Precision intraday

\begin{tabular}{|c|c|c|c|c|c|c|c|}
\hline \multirow[t]{2}{*}{ S. No. } & \multirow[t]{2}{*}{ Concentration } & \multicolumn{3}{|c|}{ Absorbance } & \multirow[t]{2}{*}{ Mean } & \multirow[t]{2}{*}{ Standard deviation } & \multirow[t]{2}{*}{ \% RSD } \\
\hline & & $\mathrm{I}$ & II & III & & & \\
\hline 1. & 12.5 & 0.0735 & 0.0747 & 0.0744 & 0.0744 & 0.000874 & 1.1732 \\
\hline 2. & 25 & 0.1434 & 0.1435 & 0.1465 & 0.1444 & 0.00176 & 1.2194 \\
\hline 3. & 37.5 & 0.2189 & 0.2208 & 0.2185 & 0.2194 & 0.00122 & 0.5600 \\
\hline 4. & 50 & 0.2886 & 0.2970 & 0.2932 & 0.2929 & 0.00420 & 1.14359 \\
\hline 5. & 67.5 & 0.3772 & 0.3692 & 0.3800 & 0.3754 & 0.00560 & 1.4927 \\
\hline 6. & 75 & 0.4593 & 0.4526 & 0.4610 & 0.4576 & 0.00444 & 0.9704 \\
\hline
\end{tabular}




\section{AUTHORS CONTRIBUTIONS}

All the author have contributed equally

\section{CONFLICT OF INTERESTS}

Declare none

\section{REFERENCES}

1. Indian Pharmacopiea. Delhi: Controller of publications; 1996. p. 668-70.

2. Healy A, Deirdre C, Owen C. Physicochemical and in vitro deposition properties of salbutamol sulphate/ipratropium bromide and salbutamol sulphate/excipients spray-dried mixtures for use in dry powder inhalers. Int J Pharm 2006;322:22-30.

3. http://www.apvma.gov.au [Last accessed on 10 Apr 2019]

4. ICH harmonized tripartite guideline: validation of analytical procedures: text and methodology Q2 (R1); 2005.

5. Sonawane S, Shirkhedkar A, Fursule Ravindra A, Surana S Application of UV spectrophotometry and RP-HPLC for simultaneous determination of atorvastatin calcium and ezetimibe in the pharmaceutical dosage form. Eurasian J Anal Chem 2006;1:31-41.

6. Verma S, Alam O, Mullick P, Siddiqui N, Khan S. Validated, ultraviolet spectroscopy method for the dissolution study of mycophenolate mofetil immediate release $500 \mathrm{mg}$ tablets. Nat Precedings Doi:10.1038/npre.2008.2250. 